|Araştırma Makalesi / Research Article|

\title{
Disleksili Olan ve Olmayan Öğrencilerin Sözel Dil Becerilerinin İncelenmesi
}

\section{Examination of Oral Language Skills of Students with Dyslexia}

\section{Şaziye Seçkin Yılmaz ${ }^{1}$, Kıymet Rümeysa Sarı²}

Anahtar Kelimele
disleksi
sözcük bilgisi
biçimbirim bilgisi
sözdizimi
dilbilgisi
sözel dil

\section{Keywords}

dyslexia

vocabulary

morphology

syntax

morpho-syntax

oral language

\section{Başvuru Tarihi/Received}

15.08.2019

Kabul Tarihi /Accepted

30.04.2020
Öz

Disleksideki okuma sorunları fonolojik işlemleme becerilerindeki güçlüklerden kaynaklanmaktadır. Fonolojik işlemleme becerilerindeki güçlüklere sözel dil güçlükleri de eşlik ettiğinde okuma sorunları daha da artmaktadır. Bu çalışmada disleksili öğrencilerin sözel dil becerilerinin tipik gelişim gösteren (TGG) akranları ile karşılaştırılması amaçlanmaktadır. Çalışmanın katılımcılarını ilkokul üçüncü sınıfa devam eden okumada disleksi tanılı 30 ve TGG 30 olmak üzere 60 öğrenci oluşturmaktadır. Verilerin toplanması amacı ile Türkçe Okul Çağı Dil Gelişimi Testi kullanılmıştır. Test öğrencilere birebir uygulanmış, verilerin analizinde SPSS 24 paket programı kullanılmışır. Grupların testin alt testlerinden elde ettikleri puanlar normal dağıım göstermediği için grupların karşılaştııılmasında Mann Whitney U testi kullanılmıştır. Gruplar arası farklılaşmalara ilişkin etki büyüklükleri de hesaplanmıştır. Ayrıca çalışmaya katılan öğrencilerin testten aldıkları puanlar testin normları ile de karşılaştırılmıştır. Sonuçlar disleksili öğrencilerin TGG akranlarına göre daha düşük sözel dil performansı gösterdiklerini, gruplar arası farklılaşmaya ilişkin etki büyüklüklerinin orta düzeyde olduğunu göstermiştir. Katılımcıların puanları test normu ile karşılaştıııldığında disleksili öğrencilerin önemli bir kısmının zayıf ve çok zayıf sözel dil performansına sahip olduğu görülmüştür. TGG öğrencilerden ise zayıf ve çok zayıf sözel dil performansı gösteren olmamıştır. Çalışmanın bulguları ilgili alanyazın doğrultusunda tartışılmış, sonraki araştırmalara ve uygulamaya yönelik öneriler sunulmuştur.

\section{Abstract}

Reading problems in dyslexia arise from difficulties in phonological processing skills. Reading difficulties increase even more when oral language difficulties accompany phonological processing skills. This study aims to compare the oral language skills of the students with dyslexia with those of their peers with typical development. The participants of the study consist of a total of 60 primary school third-grade students, 30 of whom were diagnosed with dyslexia and the remaining 30 of whom with typical development. To collect the data, Test of Language Development was used. The data were analysed through the SPSS 24 package program. Since the scores that the groups obtained from the subtests of the test do not show a normal distribution, the Mann Whitney $\mathrm{U}$ test was used to compare the groups. In addition, the effect sizes for the differentiation between the groups were calculated. Also, the scores of the students who participated in the study were compared with the norms of the test. The results showed that the students with dyslexia had lower oral language performance than their peers with typical development and the effect sizes for differentiation between the groups were moderate. When the participants' scores were compared with the test norm, it was observed that a significant number of the students with dyslexia had poor and very poor oral language performance. On the other hand, none of the students with typical development showed poor or very poor oral language performance. The findings of the study were discussed in light of the related literature and suggestions for further research and practice were presented.

${ }^{1}$ Üsküdar Üniversitesi, Sağlık Bilimleri Fakültesi, Dil ve Konuşma Terapisi Bölümü, İstanbul, TÜRKiYE, https://orcid.org/0000-0003-0488-9639 ${ }^{2}$ Hilal Karadeniz Özel Eğitim ve Rehabilitasyon Merkezi, İstanbul, TÜRKiYE, https://orcid.org/0000-0001-9190-6067 
Extended Abstract

\section{Introduction}

Dyslexia is a genetic and neurodevelopmental disorder, which is diagnosed by an individual's "unexpected" failure to learn reading and develop reading skills despite having a normal intelligence or above the normal, having adequate environmental and instructional opportunities, and not having any deficiencies (visual impairment, hearing impairment, neurological disorder). The cause of dyslexia is unknown; however, dyslexia is defined as a language-based disorder (American Psychiatric Association (APA), 2013; Lyon, Shaywitz \& Shaywitz, 2003; Ziegler, Perry, Ma-Wyatt, Ladner \& Schulte-Korne, 2003).

Numerous studies have shown that children with dyslexia are less successful in phonological awareness, rapid automized naming and phonological short-term memory assessments than their peers, and these skills, called phonological processing skills, pre-dict an individual's reading success (Catts, Fey, Zhang, \& Tomblin, 1999; Dandache, Wouters, \& Ghesquière; 2014; Knoop-van Campen, Segers, \&Verhoeven, 2018; Moura, Moreno, Pereira, \& Simões, 2015; Wimmer \& Schurz, 2010). Although there is a consensus on dysfunction in the phonological component of language in individuals with dyslexia, studies on oral language skills are more recent and few. It is known that individuals with dyslexia also have serious difficulties in oral language components such as vocabulary, morphology and syntax and that these difficulties cause difficulties in reading comprehension (Adlof \& Hogan, 2018; Chick et al., 2012; Hulme \& Snowling, 2016; Van der Lely \& Marshall, 2010).

In the international literature, there are many studies on the oral language skills of children with dyslexia and the number of these studies is increasing. Yet, there is no study on the subject found in the national literature. In line with these necessities, this study aims to compare the oral language skills of third-grade students with dyslexia to those of their peers with typical development who have no difficulty in reading and to examine them according to the norms of the Test of Language Development, which is a norm referenced standardized oral language test.

\section{Method}

In this study, oral language skills of primary school 3rd-grade students with dyslexia and their peers with typical development were examined comparatively. For this purpose, the comparative descriptive research design was used in the study. The participants of the study consist of a total of 60 primary school third-grade students who was born in 2010, 30 of whom were diagnosed with dyslexia and the remaining 30 of whom with typical development according to their classroom teachers' statements. To collect the data, Turkish version of the Test of Language Development, Primary (TOLD-P:4) was used. The data were collected by working with the students individually. The assessments lasted 45-60 minutes for each student.

The data were analyzed through the SPSS 24 . In relation to the dependent variables studied, descriptive statistics and ShapiroWilk normality test were performed. The significance of the score differences in the comparisons between the groups was examined through the Mann Whitney $U$ Test since the data did not show a normal distribution. To examine the effect sizes of the values obtained from the comparison of the groups, Cohen's effect size formula (d) (1988) was used. In addition, the raw scores of the students were converted to standard scores and analysed according to the TOLD-P: 4 norm.

\section{Result and Discussion}

In the picture vocabulary, relational vocabulary and oral vocabulary subtests, the students with dyslexia scored significantly lower than their peers with typical development, the effect sizes of the differences between the groups are moderate. When the students' vocabularies were examined according to the test norm, it was seen that 20 of the students with dyslexia had poor and very poor performance. On the other hand, none of the students with typical development showed poor or very poor performance. In the morphological completion, syntactic understanding and sentence imitation subtests, the students with dyslexia scored significantly lower than their peers with typical development; the effect sizes of the differences between the groups are moderate. When the students' grammar scores were examined according to the test norm, it was seen that 20 of the students with dyslexia had poor and very poor performance. On the other hand, only one of the students with typical development showed poor performance. The students with dyslexia received significantly lower oral language scores than their typical developing peers, and the effect size for the differentiation between the groups is moderate. 5 of the students with dyslexia showed poor performance and 16 of them showed very poor performance; while none of the students with typical development showed poor or very poor performance.

In this study, it was seen that oral language performances of the students with dyslexia were lower than their peers with typical development and than the norms in the standardized language test. It is also stated in the literature that students with dyslexia receive lower scores than both their peers who have no difficulty in reading and the standard test norms (Adlof \& Hogan, 2018). The fact that 16 of the students in the group with dyslexia showed very poor performance when the oral language performances of the groups were examined according to the test norm has made us think that these students may also have a developmental language disorder. This number constitutes 53\% of the group. Moreover, it is stated in the literature that $55 \%$ of children with dyslexia also have developmental language disorders (McArthur et al., 2000). When dyslexia is accompanied by a developmental language disorder, the picture becomes more severe and difficulties in word reading are followed by difficulties in reading comprehension (Adlof \& Hogan, 2018). Therefore, assessments and interventions for oral language skills of students with dyslexia are especially crucial to reduce the difficulties in reading comprehension. 
Disleksi, yüz yıldan uzun bir süredir alanyazında yer almasına karşın, halen tam olarak anlaşılabilmiş değildir. Araştırmalar disleksinin yalnızca okuma becerilerinde yaşanan güçlüklerle tanımlanamayacağını göstermektedir. Güncel disleksi araştırmaları dislekside buzdağının görünen yüzü olan okuma güçlüklerinden çok bu güçlüklerin altında yatan nedenlere odaklanmaktadır. Son tanı ölçütlerinde de disleksinin dil temelli bir bozukluk olduğu vurgulanmaktadır. Ancak disleksili öğrencilerin tek sorunu dilin fonoloji bileşeninde ve sözcük çözümlemede değildir. Sözel dil becerilerindeki güçlükler ve okuduğunu anlama sorunları da disleksiye sıklıkla eşlik etmektedir.

Son Tanı Ölçütleri Başvuru El Kitabı'na göre disleksi bireyin normal veya üzerinde zekâya, yeterli çevresel ve öğretimsel fırsatlara sahip olmasına ve herhangi bir yetersizliği (görme, işitme yetersizliği, nörolojik bozukluk) olmamasına karşın okumayı öğrenmede ve okuma becerilerini geliştirmede "beklenmedik" bir şekilde başarısız olması ile tanılanan, genetik geçiş gösteren, nöro-gelişimsel bir bozukluktur. Disleksili öğrenciler harf-ses ilişkisi kurmayı öğrenmede, sözcük okuma becerilerini geliştirmede, akıcı okumada ve okuduğunu anlamada güçlük yaşarlar (American Psychiatric Association (APA), 2013; Lyon, Shaywitz ve Shaywitz, 2003; Ziegler, Perry, Ma-Wyatt, Ladner ve Schulte-Korne, 2003). Disleksi dil temelli bir bozukluk olarak tanımlanmakta ve sözcük okuma güçlüklerinin dilin fonoloji bileşenindeki güçlüklerden kaynaklandığı belirtilmektedir. Çok sayıda çalışma disleksili öğrencilerin fonolojik işlemleme becerilerinde (fonolojik farkındalık, hızlı otomatik isimlendirme ve fonolojik kısa süreli bellek) akranlarından başarısız olduklarını ve bu becerilerin okuma başarısını yordadığını göstermektedir (Catts, Fey, Zhang ve Tomblin, 1999; Dandache, Wouters ve Ghesquière; 2014; Knoop-van Campen, Segers ve Verhoeven, 2018; Moura, Moreno, Pereira ve Simões, 2015; Wimmer ve Schurz, 2010). Disleksili bireylerde dilin fonoloji bileşenindeki bozukluk üzerinde uzlaşı olmasına karşın diğer sözel dil becerilerine ilişkin olarak yapılan çalışmalar daha yeni ve az sayıdadır. Disleksili bireylerin dilin sözcük bilgisi (anlam bilgisi, semantik), biçimbirim bilgisi (morfoloji), sözdizimi (sentaks) gibi fonoloji dışındaki sözel dil bileşenlerinde de önemli güçlükler yaşadıkları ve bu bileşenlerde yaşanan güçlüklerin sözcük çözümlemedeki güçlüklerle birlikte, okuduğunu anlama güçlüklerine neden olduğu bilinmektedir (Adlof ve Hogan, 2018; Chick ve ark., 2012; Hulme ve Snowling, 2016; Van der Lely ve Marshall, 2010).

Disleksili bireylerin sözel dil becerilerinde de güçlükler yaşamaları araştırmacıları disleksi ile gelişimsel dil bozukluğu ilişkisini incelemeye itmiştir. "Gelişimsel dil bozukluğu" bireyin normal ve normal üzerinde bir zekâya sahip olmasına, herhangi bir yetersizliğinin olmamasına (görme, işitme yetersizliği, nörolojik bozukluk), yeterli çevresel uyaran ve bilişsel becerilere sahip olmasına karşın dil becerilerinde yaşadığı "beklenmedik" güçlüğü ifade etmektedir (Leonard, 2014). Disleksi ve gelişimsel dil bozukluğu tanımları incelendiğinde her iki bozukluğun da "beklenmedik" bozukluklar olması ve benzer dışlama ölçütlerini içermesi dikkat çekicidir. Bu iki bozukluğun ayrı fakat birlikte görülebilen bozukluklar olduğu belirtilmektedir (Adlof ve Hogan, 2018). Disleksili öğrencilerin sözel dil becerilerinin gelişimsel dil bozukluğu bağlamında incelendiği çalışmalar disleksili öğrencilerin önemli bir kısmında dil bozukluğu da olduğunu (Arosio, Pagliarini, Perugini, Barbieri ve Guasti, 2016; McArthur, Hogben, Edwards, Heath ve Mengler, 2000), dil bozukluğu olmayan yalnızca disleksisi olan öğrencilerin de bozukluk boyutunda olmasa da sözel dil becerilerinde normal gelişim gösteren akranları kadar başarılı olmadığını (Adlof, Scoggins, Brazendale, Babb ve Petscher, 2017; McArthur ve ark., 2000) göstermektedir. Disleksili birçok çocuğun sözcük bilgisi (Bishop, McDonald, Bird ve Hayiou-Thomas, 2009), biçimbirim bilgisi (Cantiani, Lorusso, Perego, Molteni ve Guasti, 2015; Joanisse, Manis, Keating, ve Seidenberg, 2000) ve sözdiziminde (Cantiani, Lorusso, Perego, Molteni ve Guasti, 2013) önemli güçlükleri bulunmaktadır.

Disleksili öğrencilerin dil becerilerindeki güçlüklerinde araştırma konusu olan bir başka konu da güçlüklerin ortaya çıkış zamanı ile ilgilidir. Çünkü okuma ve dil becerileri karşılıklı olarak birbirini etkilemektedir. Dil becerileri güçlü olan öğrenciler okuma için iyi bir altyapıya sahiptirler. Ayrıca okuma becerileri gelişmiş olan öğrenciler de okuma sırasında daha fazla sayıda ve karmaşık sözcük, biçimbirim ve sözdizimsel yapıya maruz kaldıklarından dil becerilerini geliştirme fırsatına sahip olurlar (Ricketts, Nation ve Bishop, 2007; Verhoeven ve Perfetti, 2011). Disleksili öğrencilerin dil becerilerinde yaşadıkları güçlüklerin okuma öğrenmeden önceki dönemde var olup olmadığının belirlenebilmesi için ailesinde disleksi öyküsü olan ve/veya dil ve konuşma becerilerinde gecikmesi olan öğrenciler boylamsal olarak izlenmişlerdir. Bu boylamsal araştırmalar okul döneminde disleksi tanısı alan öğrencilerin sözel becerilerindeki güçlüklerinin okul öncesi dönemde de var olduğunu; güçlüklerin yalnızca okuma deneyimlerinin eksikliği nedeniyle, okuma yoluyla dil becerilerinin geliştirilememesinden kaynaklanmadığını göstermektedir (Hulme, Nash, Gooch, Lervåg ve Snowling, 2015; Hulme ve Snowling, 2016; Lyytinen ve Lyytinen, 2004).

Özetle disleksili öğrencilerin önemli bir kısmı fonoloji dışındaki sözel dil becerilerinde de önemli güçlükler yaşamaktadırlar. Fonoloji ve okuma becerilerinin yanında sözel dil becerilerinin de değerlendirilmesi; disleksinin doğasının daha iyi anlaşılması, disleksiye eşlik eden sözel dil bozukluklarının belirlenmesi ve dil bozukluğu yaşayan disleksili öğrencilerin okuma ve dilin fonoloji bileşenindeki bozukluklara yönelik müdahalelerin yanında sözel dil bozukluklarına yönelik de müdahale alabilmeleri için önemlidir.

Uluslararası alanyazında disleksili öğrencilerin sözel dil becerilerinin incelenmesine yönelik çalışmaların artarak devam ettiği görülmektedir. Ulusal alanyazında ise konuyla ilgili yalnızca bir çalışmaya ulaşılmıştır. Söz konusu çalışmada sözel dil bileşenlerinden yalnızca sözcük bilgisinin resim-sözcük dağarcığı bağlamında değerlendirildiği ve okumada öğrenme güçlüğü yaşayan (disleksili) öğrencilerin TGG akranlarına göre daha sınırlı sözcük dağarcığına sahip oldukları görülmüştür (Delimehmet Dada ve Ergül, 2020). Okuma becerilerine ve dilin fonoloji bileşenine ek olarak sözel dil becerilerinin de değerlendirilmesi, Türkçe konuşan öğrencilerde disleksinin doğasının anlaşılması ve disleksili öğrencilerin Türkçe'de yaşadıkları dile özgü sorunların olup olmadığının belirlenmesi için önemlidir. Ayrıca disleksili öğrencilerin okuma sorunları dışında sözel dil becerilerinde de sorun yaşamaları halinde sözel dil becerilerine yönelik müdahale alabilmeleri hem dil hem de okuduğunu anlama becerilerinin

| Kastamonu Eğitim Dergisi, 2020, Vol. 28, No. 4| 
geliştirilmesi için gereklidir. Belirtilen gereksinimler doğrultusunda, bu çalışmanın amacı disleksi tanılı ilkokul üçüncü sınıf öğrencilerinin sözel dil becerilerinin TGG akranları ile karşılaştırılması ve standardize bir sözel dil testi olan Türkçe Okul Çağı Dil Gelişimi Testi-TODiL (Topbaş ve Güven, 2017) normlarına göre incelenmesidir. Çalışmada şu sorulara yanıt aranmıştır:

1. Disleksili öğrencilerin sözcük bilgisi performansları TGG akranlarının sözcük bilgisi performanslarından anlamlı bir şekilde farklılaşmakta mıdır?

2. Disleksili ve TGG öğrencilerin sözcük bilgisi performansları TODiL normuna göre nasıldır?

3. Disleksili öğrencilerin dil bilgisi performansları TGG akranlarının dilbilgisi performanslarından anlamlı bir şekilde farklılaşmakta mıdır?

4. Disleksili ve TGG öğrencilerin dil bilgisi performansları TODiL normuna göre nasıldır?

5. Disleksili öğrencilerin sözel dil toplam puanları TGG akranlarınınkinden anlamlı bir şekilde farklılaşmakta mıdır?

6. Disleksili ve TGG gösteren öğrencilerin toplam sözel dil puanları TODíL normuna göre nasıldır?

\section{YÖNTEM}

\section{Araştırma Deseni}

Bu araştırmada ilkokul üçüncü sınıfa devam eden disleksi tanısı olan ve TGG öğrencilerin sözel dil becerileri karşılaştırmalı olarak incelenmiştir. Bu amaçla çalışmada karşılaştırmalı betimsel araştırma modeli kullanılmıştır. Bu araştırma modelinde öncelikle karşılaştırılacak grupların belli değişkenler açısından, ortak ölçekler kullanılarak ayrıntılı betimlemeleri yapılmakta; ikinci aşamada ise yapılan bu betimlemeler karşılaştırılmaktadır (Karasar, 2010).

\section{Çalışma Grubu}

Araştırmanın çalışma grubunu ilkokul üçüncü sınıfa devam eden, anadili Türkçe olan, 2010 yılında doğan ve okumada yaşadıkları öğrenme güçlüğü nedeni ile öğrenme güçlüğü (disleksi) tanısı olan 30 (17 kız, 13 erkek) ve sınıf öğretmenlerinin tipik gelişim gösterdiklerini belirttikleri 30 (16 kız, 14 erkek) olmak üzere toplam 60 öğrenci oluşturmaktadır. TGG öğrencilerin belirlenmesinde 2010 yılı doğumlu olma, anadilinin Türkçe olması, herhangi bir yetersizliğinin (zihin, görme, işitme yetersizliği, nörolojik bir bozukluk) veya yetersizlik şüphesinin olmaması, akıcı okuma ve okuduğunu anlamada sorun yaşamama ölçütleri dikkate alınmıştır.

\section{Veri Toplama Aracı}

Çalışmada öğrencilerin sözel dil performanslarının karşılaştırılması amacı ile TODí (Topbaş ve Güven, 2017) kullanılmıştır. Bu test, Test of Language Development, Primary'nin (TOLD-P:4; Hammill ve Newcomer, 2008) Türkçeye uyarlamasıdır. Standart bir test olan TODiL, 4.0 ile 8 yaş 11 ay grubundaki çocukların sözel dil becerilerinin değerlendirilmesinde kullanılmaktadır. Bu test resim sözcük dağarcığı, ilişkili sözcük dağarcığı, sözcük betimleme, cümle anlama, cümle tekrarı, biçimbirim tamamlama olmak üzere altı ana alt test ve sözcük ayırt etme, sesbirimsel analiz ve sözcük sesletimi ek alt testleri olmak üzere toplam 9 alt testten oluşmaktadır. Bu çalışmada testin ana alt testleri kullanılmıştır.

Resim-sözcük dağarcığı alt testinde katılımcılardan aynı sayfaya basılı dört resimden adı söyleneni göstermesi beklenmektedir. iliş̧kili sözcük dağarcığı alt testinde katılımcılara iki sözcük söylenmekte ve bu sözcükler arasındaki ilişkiyi ifade etmeleri beklenmektedir. Sözcük betimleme alt testinde katılımcılardan söylenen sözcüğü betimlemesi istenmektedir. Biçimbirim tamamlama alt testinde katılımcıların söylenen cümledeki boşluğu uygun biçimbirimi içeren sözcükle tamamlaması gerekmektedir. Cümle anlama alt testinde katılımcılardan aynı sayfaya basılı dört resimden söylenen cümleyi ifade edeni göstermesi beklenmektedir. Cümle tekrarı alt testinde katılımcılardan söylenen cümleyi değiştirmeden söylenen şekilde tekrar etmesi istenmektedir.

\section{Verilerin Toplanması}

Veriler 2018 yılının aralık ve 2019 yılının ocak aylarında öğrencilerin devam ettikleri özel eğitim ve rehabilitasyon merkezlerinde ve ilkokullarda toplanmıştır. Değerlendirme oturumları öğrencilerle bireysel olarak sessiz bir ortamda yapılmıştır. Çalışmaya başlanmadan önce öğrencilerin ortama ve uygulamacıya uyum sağlayabilmesi için kısa bir süre sohbet edilmiş ve öğrenciye yapılacak çalışmalar hakkında bilgi verilmiştir.

Tüm alt testlerde katılımcılar doğru yanıtları için "1", yanlış yanıtları için "0" puan almışlardır (Katılımcıların puan alabilecekleri ve alamayacakları durumlar testte açıkça belirtilmiştir. Alt testler, öğrenciler ardışık olarak beş maddeye yanlış yanıt verdiğinde sonlandırılmıştır. Değerlendirmeler her bir öğrenci için 45-60 dakika sürmüştür.

\section{Verilerin Analizi}

Verilerin analizi için "Sosyal Bilimler İçin Veri Analizi Paket Programı (SPSS) 24" kullanılmıştır. Öncelikle grupların alt testlerden aldıkları ham puanlara ilişkin betimsel istatistikler ve Shapiro-Wilk normallik testi yapılmıştır. Gruplar arası karşılaştırmalarda puan farklılıklarının anlamlıı̆̆ı, veriler normal dağılım göstermediği için, Mann Whitney U Testi ile incelenmiştir. Grupların karşılaştırılması sonucunda elde edilen değerlerin etki büyüklüklerinin incelenmesi için Cohen'in (1988) etki büyüklügü̈ hesaplama 
formülü $(d)$ kullanılmıştır. Etki büyüklüğü (d değeri) .20'den küçük ise zayıf, .50 olması durumunda orta ve .80 'den büyük ise güçlü olarak değerlendirilmiştir (Yıldırım ve Yıldırım, 2011).

Grupların puanlarının TODiL normuna göre incelenmesi amacı ile öğerncilerin alt testlerden aldıkları ham puanlar standart puanlara dönüştürülmüş ve her öğrencinin puanı yaş normuna göre incelenmiştir. Resim sözcük dağarcığı, ilişkili sözcük dağarcığı ve sözcük betimleme alt testlerinden alınan standart puanlar toplamı sözcük bilgisi bileşke performansını; biçimbirim tamamlama, cümle anlama ve cümle tekrarı alt testlerinden alınan standart puanlar dil bilgisi bileşke performansını; sözcük bilgisi ile dil bilgisi standart puanlar toplamı da toplam sözel dil bileşke performansını oluşturmuştur. Alt testlere ve bileşke performanslara ilişkin standart puanlar testin normuna göre çok zayıf, zayıf, ortalama altı, ortalama, ortalama üstü, ileri ve çok ileri kategorilerinde sınıflandırılarak her iki katılımcı gruptan bu kategorilerde yer alan öğrenci sayısı belirlenmiştir.

\section{BULGULAR}

\section{Sözcük Bilgisine iliş̧kin Bulgular}

Tablo 1'de disleksili ve TGG öğrencilerin resim sözcük dağarcığı, ilişkili sözcük dağarcığı ve sözcük betimleme performanslarının karşılaştırılmasına ilişkin bulgular sunulmaktadır.

Tablo 1. Disleksili ve TGG öğrencilerin sözcük bilgisi performanslarının karşılaştırılması

\begin{tabular}{|c|c|c|c|c|c|c|c|c|c|}
\hline Değişken & Grup & $\mathrm{n}$ & $\bar{X}$ & SS & Sıra Ortalaması & Sıra Toplamı & $U$ & $p$ & Etki \\
\hline \multirow{2}{*}{ Resim-Sözcük Dağarcığı } & Disleksi & 30 & 23.86 & 6.22 & 20.20 & 606.00 & 141.00 & $.00 *$ & .54 \\
\hline & TGG & 30 & 29.93 & 2.40 & 40.80 & 1224.00 & & & \\
\hline \multirow{2}{*}{ İlişkili Sözcük Dağarcığı } & Disleksi & 30 & 15.00 & 7.37 & 17.42 & 522.50 & 57.50 & $.00^{*}$ & .74 \\
\hline & TGG & 30 & 28.16 & 3.63 & 43.58 & 1307.50 & & & \\
\hline \multirow{2}{*}{ Sözcük Betimleme } & Disleksi & 30 & 19.20 & 6.81 & 17.30 & 519.00 & 54.00 & $.00^{*}$ & .75 \\
\hline & TGG & 30 & 32.10 & 3.97 & 43.70 & 1311.00 & & & \\
\hline
\end{tabular}
${ }^{*} p<.05$

Tablo 1 incelendiğinde disleksi tanılı öğrencilerin resim sözcük dağarcığı $(U=141.00, p<.05, d=.54)$, ilişkili sözcük dağarcığı (U= $57.50, p<.05, d=.74)$ ve sözcük betimleme $(U=54.00, p<.05, d=.75)$ alt testlerinde TGG akranlarından anlamlı bir şekilde düşük puanlar aldığı ve gruplar arasındaki farklılaşmalara ilişkin etki büyüklüklerinin orta düzeyde olduğu görülmektedir.

Tablo 2'de disleksili ve TGG öğrencilerin sözcük bilgisi performanslarının TODiL normuna göre incelenmesine ilişkin sonuçlar sunulmaktadır.

Tablo 2. Disleksili ve TGG öğrencilerin sözcük bilgisi performanslarının TODiL normuna göre incelenmesi

\begin{tabular}{|c|c|c|c|}
\hline \multirow[t]{2}{*}{ Değişken } & \multirow[t]{2}{*}{ TODIL Tanımlayıcı Terim } & \multicolumn{2}{|c|}{ Grup } \\
\hline & & Disleksi & TGG \\
\hline \multirow{6}{*}{ Resim Sözcük Dağarcığı } & ileri & 0 & 0 \\
\hline & Ortalama üstü & 2 & 7 \\
\hline & Ortalama & 11 & 21 \\
\hline & Ortalama altı & 6 & 2 \\
\hline & Zayıf & 5 & 0 \\
\hline & Çok zayıf & 6 & 0 \\
\hline \multirow{7}{*}{ îlişkili Sözcük Dağarcığı } & Çok Illeri & 0 & 1 \\
\hline & İleri & 1 & 7 \\
\hline & Ortalama üstü & 1 & 14 \\
\hline & Ortalama & 5 & 8 \\
\hline & Ortalama altı & 5 & 0 \\
\hline & Zayıf & 5 & 0 \\
\hline & Çok zayıf & 13 & 0 \\
\hline \multirow{7}{*}{ Sözcük Betimleme } & Çok ileri & 0 & 1 \\
\hline & İleri & 1 & 6 \\
\hline & Ortalama üstü & 1 & 12 \\
\hline & Ortalama & 6 & 10 \\
\hline & Ortalama altı & 3 & 1 \\
\hline & Zayıf & 8 & 0 \\
\hline & Çok zayıf & 11 & 0 \\
\hline \multirow{7}{*}{ Sözcük Bilgisi Bileşke Puanı } & Çok Illeri & 1 & 0 \\
\hline & İleri & 0 & 7 \\
\hline & Ortalama üstü & 1 & 11 \\
\hline & Ortalama & 5 & 12 \\
\hline & Ortalama altı & 3 & 0 \\
\hline & Zayıf & 6 & 0 \\
\hline & Çok zayıf & 14 & 0 \\
\hline
\end{tabular}


Tablo 2 incelendiğinde resim-sözcük dağarcığı alt testinde disleksili öğrencilerden 11'inin zayıf ve çok zayıf performans gösterdiği, TGG öğrencilerden zayıf ve çok zayıf performans gösteren olmadığı; ilişkili sözcük dağarcı̆̆ı alt testinde disleksili öğrencilerden 18'inin zayıf ve çok zayıf performans gösterdiği, TGG öğrencilerden zayıf ve çok zayıf performans gösteren olmadığı görülmektedir. Sözcük betimleme alt testinde disleksili öğrencilerden 19’u zayıf ve çok zayıf performans gösterirken, TGG öğrencilerden zayıf ve çok zayıf performans gösteren olmamıştır. Anlam bilgisi bileşke puanlarında disleksili öğrencilerden 20'sinin zayıf ve çok zayıf performans gösterdiği, TGG öğrencilerden zayıf ve çok zayıf performans gösteren olmadığı görülmektedir.

\section{Dil Bilgisine İlişkin Bulgular}

Tablo 3'te disleksili ve TGG öğrencilerin dil bilgisi performanslarının karşılaştırılmasına ilişkin bulgular sunulmaktadır.

Tablo 3. Disleksili ve TGG öğrencilerin dil bilgisi performanslarının karşılaştırılması

\begin{tabular}{|c|c|c|c|c|c|c|c|c|c|}
\hline Değişken & Grup & $\mathrm{n}$ & $\bar{x}$ & SS & Sıra Ortalaması & Sıra Toplamı & $U$ & $p$ & Etki \\
\hline \multirow{2}{*}{ Cümle Anlama } & Disleksi & 30 & 20.66 & 4.66 & 17.38 & 521.50 & 56.50 & $.00^{*}$ & .67 \\
\hline & TGG & 30 & 27.33 & 2.24 & 43.62 & 1308.50 & & & \\
\hline \multirow{2}{*}{ Cümle Tekrar Etme } & Disleksi & 30 & 15.30 & 6.08 & 16.73 & 502.00 & 37.00 & $.00 *$ & .78 \\
\hline & TGG & 30 & 28.96 & 4.45 & 44.27 & 1328.00 & & & \\
\hline \multirow{2}{*}{ Biçimbirim Tamamlama } & Disleksi & 30 & 24.56 & 5.08 & 17.25 & 548.00 & 83.00 & $.00^{*}$ & .66 \\
\hline & TGG & 30 & 32.63 & 3.82 & 43.75 & 1282.00 & & & \\
\hline
\end{tabular}

${ }^{*} p<.05$

Tablo 3 incelendiğinde disleksi tanılı̈ örencilerin cümle anlama $(U=56.50, p<.05, d=.67)$, cümle tekrar etme $(U=37.00, p<.05$, $d=.78)$ ve biçimbirim tamamlama $(U=83.00, p<.05, d=.66)$ alt testlerinde TGG akranlarından anlamlı bir şekilde düşük puanlar aldıkları ve gruplar arasındaki farklılaşmalara ilişkin etki büyüklüklerinin orta düzeyde olduğu görülmektedir.

Tablo 4'te disleksili ve TGG öğrencilerin dil bilgisi performanslarının TODíL normuna göre incelenmesine ilişkin bulgular sunulmaktadır.

Tablo 4. Disleksili ve TGG öğrencilerin dil bilgisi performanslarının TODiL normuna göre incelenmesi

\begin{tabular}{|c|c|c|c|}
\hline \multirow[t]{2}{*}{ Değişken } & \multirow[t]{2}{*}{ TODiL Tanımlayıcı Terim } & \multicolumn{2}{|c|}{ Grup } \\
\hline & & Disleksi & TGG \\
\hline \multirow{7}{*}{ Cümle Anlama } & Çok Illeri & 0 & 0 \\
\hline & İleri & 0 & 1 \\
\hline & Ortalama üstü & 1 & 2 \\
\hline & Ortalama & 8 & 27 \\
\hline & Ortalama altı & 10 & 0 \\
\hline & Zayıf & 3 & 0 \\
\hline & Çok zayıf & 8 & 0 \\
\hline \multirow{7}{*}{ Cümle Tekrar } & Çok İleri & 0 & 1 \\
\hline & İleri & 1 & 7 \\
\hline & Ortalama üstü & 0 & 5 \\
\hline & Ortalama & 3 & 22 \\
\hline & Ortalama altı & 4 & 2 \\
\hline & Zayıf & 7 & 0 \\
\hline & Çok zayıf & 16 & 1 \\
\hline \multirow{7}{*}{ Biçimbirim Tamamlama } & Çok İleri & 0 & 1 \\
\hline & İleri & 1 & 6 \\
\hline & Ortalama üstü & 0 & 7 \\
\hline & Ortalama & 9 & 21 \\
\hline & Ortalama altı & 11 & 2 \\
\hline & Zayıf & 6 & 0 \\
\hline & Çok zayıf & 4 & 0 \\
\hline \multirow{7}{*}{ Dil Bilgisi Bileşke Puanı } & Çok Ileri & 0 & 1 \\
\hline & İleri & 0 & 1 \\
\hline & Ortalama üstü & 0 & 4 \\
\hline & Ortalama & 3 & 23 \\
\hline & Ortalama altı & 7 & 1 \\
\hline & Zayıf & 11 & 1 \\
\hline & Çok zayıf & 9 & 0 \\
\hline
\end{tabular}

Tablo 4 incelendiğinde cümle anlama alt testinde disleksili öğrencilerden 11'inin zayıf ve çok zayıf performans gösterdiği, TGG öğrencilerden zayıf ve çok zayıf performans gösteren olmadığı görülmektedir. Cümle tekrar alt testinde disleksili öğrencilerden 23'ü zayıf ve çok zayıf performans gösterirken, TGG öğrencilerden biri çok zayıf performans göstermiştir. Biçimbirim tamamlama alt testinde disleksili öğrencilerden 10'unun zayıf ve çok zayıf performans gösterdiği, TGG öğrencilerden zayıf ve çok zayıf 
performans gösteren olmadığı görülmektedir. Dil bilgisi bileşke puanlarında disleksili öğrencilerden 20'sinin zayıf ve çok zayıf performans gösterdiği, TGG öğrencilerden birinin zayıf performans gösterdiği görülmektedir.

\section{Toplam Sözel Dil Puanlarına ilişsin Bulgular}

Tablo 5’te disleksili TGG öğrencilerin sözel dil bileşke performanslarının karşılaştırılmasına ilişkin bulgular sunulmaktadır. Tablo 5. Disleksili ve TGG öğrencilerin sözel dil bileşke performanslarının karşılaştırııması

\begin{tabular}{llcccccccc}
\hline Değişken & Grup & $\mathrm{n}$ & $\overline{\mathrm{X}}$ & SS & Sıra Ortalaması & Sıra Toplamı & $U$ & $\mathrm{p}$ & $E t k i$ \\
\hline \multirow{2}{*}{ Sözel Dil Bileşke Puanı } & Disleksi & 30 & 31.00 & 17.26 & 17.25 & 548.00 & 52.50 & $.00^{*}$ & .77 \\
& TGG & 30 & 68.43 & 10.26 & 43.75 & 1282.00 & & & \\
\hline
\end{tabular}
${ }^{*} p<.05$

Tablo 5 incelendiğinde disleksi tanılı öğrencilerin sözel dil bileşke puanlarının TGG akranlarından anlamlı bir şekilde düşük olduğu ve gruplar arasındaki farklılaşmanın etki büyüklüğünün orta düzeyde olduğu görülmektedir $(U=52.50, p<.05, d=.77)$.

Tablo 6'da disleksili ve TGG öğrencilerin sözel dil bileşke puanlarının TODiL'e göre incelenmesine ilişkin bilgiler sunulmaktadır. Tablo 6. Disleksili ve TGG öğrencilerin sözel dil bileşke puanlarının TODiL’e göre incelenmesi

\begin{tabular}{|c|c|c|c|}
\hline \multirow[t]{2}{*}{ Değişken } & \multirow[t]{2}{*}{ TODIL Tanımlayıcı Terim } & \multicolumn{2}{|c|}{ Grup } \\
\hline & & Disleksi & TGG \\
\hline \multirow{7}{*}{ Sözel Dil Bileşke Puanı } & Çok Ileri & 0 & 0 \\
\hline & İleri & 0 & 4 \\
\hline & Ortalama üstü & 1 & 8 \\
\hline & Ortalama & 3 & 17 \\
\hline & Ortalama altı & 5 & 1 \\
\hline & Zayıf & 5 & 0 \\
\hline & Çok zayıf & 16 & 0 \\
\hline
\end{tabular}

Tablo 6 incelendiğinde sözel dil bileşke puanında disleksili öğrencilerden 5'inin zayıf, 16'sının çok zayıf performans gösterdiği, TGG öğrencilerden zayıf ve çok zayıf performans gösteren olmadığı görülmektedir.

\section{TARTIŞMA}

Bu çalışmada disleksi tanısı olan öğrencilerin sözel dil becerilerinin tipik gelişim gösteren akranlarının sözel dil becerileri ve değerlendirmede kullanılan testin normu ile karşılaştırmalı olarak incelenmesi amaçlanmıştır. Sonuçlar sözel dilin tüm alt bileşenlerinde disleksili öğrencilerin tipik gelişim gösteren akranlarından başarısız olduğunu, disleksili öğrencilerin önemli bir kısmının testin normuna göre de zayıf ve çok zayıf performans gösterdiğini, tipik gelişim gösteren gruptaki öğrencilerden ise testin normuna göre zayıf ve çok zayıf performans gösteren olmadığını göstermiştir.

Çalışmada ilk incelenen değişken sözcük bilgisidir. Disleksi tanılı öğrenciler söylenen sözcüğe ait resmi göstermeleri gereken resim sözcük dağarcığı, iki sözcük arasındaki ilişkiyi açıklamaları gereken ilişkili sözcük dağarcığı ve verilen sözcüğü betimlemeleri gereken sözcük betimleme alt testlerinde tipik gelişim gösteren akranlarından başarısız olmuşlardır. Bu değişkenlerde gruplar arasındaki farklılaşmanın derecesini belirlemek için hesaplanan etki büyüklüklerinin de orta düzeyde olduğu görülmüştür. illişkili sözcük dağarcığı ve sözcük betimlemeye ait etki büyüklüklerinin resim sözcük dağarcığına ait etki büyüklüğünden yüksek olması, ilişkili sözcük dağarcığı ve sözcük betimleme değerlendirmede disleksili öğrencilerin resim sözcük dağarcığına göre daha fazla güçlük yaşadığını göstermektedir. Yine resim sözcük dağarcığı değerlendirmesinde 11, ilişkili sözcük dağarcığı değerlendirmesinde 18 ve sözcük betimlemede 19 disleksili öğrencinin zayıf ve çok zayıf performans göstermesi, tipik gelişim gösteren öğrencilerden ise zayıf ve çok zayıf performans gösteren olmaması da ilişkili sözcük dağarcığı ve sözcük betimleme değerlendirmelerinde disleksili öğrencilerin daha çok zorlandıklarını doğrulamaktadır. Bu bulgular, disleksili öğrencilerin yaşadıkları güçlüklere ek olarak sözcük bilgisi değerlendirmelerinde farklı işlemler kullanılmasının önemini de göstermektedir. Bir sözcüğü bilmek yalnızca temsil ettiği nesne, olay, durumu bilmekle sınırlı değildir. Sözcük bilgisi; sözcüğün diğer sözcüklerle olan anlam ilişkilerini bilme ve açıklama, sözcüğün farklı bağlamlardaki anlamlarını anlama ve açıklama gibi daha üst düzey becerileri de gerektirmektedir (Delimehmet Dada ve Ergül, 2020).

Sözcük bilgisi okuduğunu anlama için önemli bir ön koşuldur. Okuduğunu anlama okunan metnin zihinsel temsilinin oluşturulması sürecidir. Metnin zihinsel temsilinin oluşturulması da metindeki sözcüklerin anlamlarını bilmekle mümkün olmaktadır (Elwér, Keenan, Olson, Byrne ve Samuelsson, 2013; Nation, Cocksey, Taylor ve Bishop, 2010). Sözcük bilgisi gelişmiş olan öğrenciler okuduklarını daha iyi anlarlar, okuduğunu daha iyi anlayan öğrenciler de metinde anlamını bilmedikleri sözcüklerle karşılaştıklarında bağlam ipuçlarından daha iyi yararlanarak bu sözcüklerin anlamlarını kendi kendilerine öğrenirler (Ritketts ve ark., 2007; Verhoeven ve Perfetti, 2011). Disleksili öğrenciler yavaş ve hatalı okudukları için okuduğunu anlamada dezavantajlılardır. Akıcı okuma sorunlarına yetersiz sözcük bilgisi de eklendiğinde okuduğunu anlama ve okuma yoluyla yeni sözcükler öğrenme bu öğrenciler için daha da zor bir hale gelmektedir. Bu nedenle sözel dil becerilerinde sorun yaşayan disleksili öğrencilerin müdahale programlarına fonolojik dil becerileri ve akıcı okuma ile ilgili amaçlarla birlikte sözcük bilgisi ve okuduğunu anlama ile ilgili amaçlar da konulmalıdır. 
Çalışmada dil bilgisi sözdizimi ve biçimbirim bilgisi becerileri temelinde incelenmiştir. Grupların sözdizimi becerileri cümle anlama ve cümle tekrarı bağlamlarında değerlendirilmiştir. Disleksili öğrenciler bu iki değerlendirmede de tipik gelişim gösteren akranları kadar başarılı olamamıştır. Etki büyüklükleri incelendiğinde gruplar arasındaki farklılaşmanın cümle tekrarında yükseğe yakın olduğu görülmektedir. Grupların performansları TODiL normuna göre incelendiğinde cümle anlamada 11, cümle tekrar etmede 23 disleksili öğrencinin zayıf ve çok zayıf performans gösterdiği; tipik gelişim gösteren öğrencilerden yalnızca birinin cümle tekrar değerlendirmesinde zayıf performans gösterdiği görülmektedir. Bu bulgular disleksili öğrencilerin hem tipik gelişim gösteren akranlarına göre hem de test normundaki akranlarına göre düşük sözdizimi performansı gösterdiklerini ve cümle tekrar değerlendirmesinde daha fazla güçlük yaşadıklarını göstermektedir. Alanyazında da disleksili öğrencilerin sözdizimi becerilerinde önemli güçlükler yaşadıkları (Cantiani ve ark., 2013; Cantiani ve ark., 2015), özellikle cümle tekrar değerlendirmesinde yaşanılan güçlüklerin arttığını gösteren çalışmalar bulunmaktadır (örn. Moll, Hulme, Nag ve Snowling, 2013). Cümle tekrarının disleksiyi daha iyi ayırt eden bir beceri olması bu becerinin kısa süreli bellek, sıralı bilgiyi değiştirmeden bellekte tutma, sesletimi planlama gibi disleksili öğrencilerin güçlük yaşadıkları bilişsel becerileri gerektirmesi ile açıklanmaktadır (Plaza, Cohen, Chevrie-Muller, 2002). Sözdiziminde yaşanılan güçlükler disleksili öğrencilerin okuduğunu anlamalarını olumsuz etkilemektedir. Sözdizimi becerilerinde yüksek performans gösteren öğrenciler cümle yapılarını daha iyi bildiklerinden bağlam ipuçlarını daha iyi yakalamakta ve anlamını bilmedikleri sözcüklerin anlamlarına kolay ulaşabilmekte, cümle ve metin düzeyinde okudukları bilgileri daha iyi birleştirebilmekte, kendi okumalarını izleyip hatalarını düzeltebilmektedirler (Cain, 2007; Oakhill, Cain ve Bryant, 2003). Bu nedenle sözel dil becerilerinde sınırlılıkları olan disleksili öğrencilere farklı cümle yapılarının öğretilmesi okuduğunu anlama başarıları için önemlidir.

Çalışmada ele alınan dil bilgisinin diğer bir boyutu biçimbirim bilgisidir. Disleksili öğrenciler cümlede bırakılan boşluğu uygun biçimbirimi içeren sözcükle tamamlamada tipik gelişim gösteren akranları kadar başarılı olamamıştır. Biçimbirim tamamlama değerlendirmesinden alınan puanlar testin norm grubuna göre incelendiğinde disleksili 10 öğrencinin zayıf ve çok zayıf performans gösterdiği, tipik gelişim gösteren öğrencilerden ise zayıf ve çok zayıf performans gösteren olmadığı görülmüştür. Alanyazında da disleksili öğrencilerin biçimbirim bilgisinde güçlükler yaşadıkları belirtilmektedir (Joanisse ve ark., 2000). Biçimbirim bilgisi okuma sırasında sözcük köklerinin ve eklerin sınırlarının fark edilmesi, sözcüklerin doğru okunarak anlamlandırılması, eklerin sözcük ve cümlelere kattıkları anlamların fark edilmesi için önemlidir. Biçimbirim bilgisi düşük olan öğrenciler okuduğunu anlamada akranlarına göre daha başarısız olmaktadır (Bowers, Kirby ve Deacon, 2010; Seçkin-Yılmaz ve Baydık 2020). Bu nedenlerde disleksili öğrencilerin biçimbirim bilgilerinin değerlendirilmesi, kullanmadıkları ve zorlandıkları biçimbirimlerin belirlenmesi ve çalışıması önemlidir.

Grupların toplam sözel dil bileşke puanları incelendiğinde disleksili öğrencilerin sözel dil toplam puanlarının tipik gelişim gösteren akranlarından daha düşük olduğu ve gruplar arasındaki farka ilişkin etki büyüklüğünün yükseğe yakın (.77) olduğu görülmüştür. Bu bulgu sözel dil performansları arasındaki farklılığın disleksi ile açıklanabileceğini göstermektedir. Grupların sözel dil puanları norma göre incelendiğinde disleksili 5 öğrencinin ortalama altı, 5 öğrencinin zayıf ve 16 öğrencinin çok zayıf sözel dil performansı gösterdiği görülmektedir. Tipik gelişim gösteren öğrencilerden ise yalnızca biri ortalama altı puan almıştır. Özellikle çok zayıf performans gösteren disleksili 16 öğrencinin (tüm grubun \%53'ü) disleksiye ek olarak gelişimsel dil bozukluğu da yaşıyor olabileceği düşünülmüştür. Disleksi tanılı büyük bir grubun standardize dil testlerinden aldıkları puanların incelendiği bir çalışmada da disleksili öğrencilerin \%55'inin aynı zamanda gelişimsel dil bozukluğu tanısı alacak kadar düşük sözel dil performansı gösterdiği, gelişimsel dil bozukluğu olmayan disleksili öğrencilerin dahi akranları kadar iyi sözel dil performansı gösteremedikleri belirtilmiştir (McArthur, Hogben, Edwards, Heath ve Mengler, 2000). Bu çalışmada da "çok zayıf" sözel dil performansı gösterenler dışındaki disleksili öğrencilerin de sözel dil becerilerinde tipik gelişim gösteren akranları kadar başarılı olamamaları alanyazın ile tutarlıdır.

\section{SONUÇ VE ÖNERILER}

Disleksili ve TGG ilkokul öğrencilerinin sözel dil becerilerinin incelendiği bu çalışmada disleksili öğrencilerin sözel dil becerilerinde hem TGG akranlarına göre hem de TODiL normuna göre düşük performans gösterdikleri görülmüştür. Uygulamada çalışan uzmanlara disleksili öğrencilerin fonoloji ve okuma becerilerine ek olarak sözel dil becerilerini de değerlendirmeleri ve desteklemeleri önerilmektedir. Sözel dil becerilerinde de güçlük yaşayan disleksili öğrencilerin okumaya ek olarak sözel dile yönelik müdahale almaları, özellikle okuduğunu anlama için önemlidir. Araştırmacılara hem disleksili hem de tipik gelişim gösteren öğrencilerin dil ve okuma becerilerini ve bu beceriler arasındaki ilişileri boylamsal olarak incelemeleri önerilmektedir. Ayrıca erken çocukluk döneminde gecikmiş dil konuşması ve/veya dil bozukluğu olan ve/veya ailesinde disleksi öyküsü bulunan çocukların dil ve okuma becerilerinin boylamsal olarak incelendiği çalışmalar yapılması dil bozukluğu ve disleksi ilişkisinin Türkçe'de de incelenebilmesi için önemlidir.

\section{KAYNAKÇA}

Adlof, S. M., \& Hogan, T. P. (2018). Understanding dyslexia in the context of developmental language disorders. Language Speech and Hearing Services in Schools, 49(4), 762-773.

Adlof, S. M., Scoggins, J., Brazendale, A., Babb, S., \& Petscher, Y. (2017). Identifying children at risk for language impairment or dyslexia with group-administered measures. Journal of Speech, Language, and Hearing Research, 60, 3507-3522.

American Psychiatric Association. (2013). Diagnostic and statistical manual of mental disorders (5th ed.). Arlington, VA: Author. 
Arosio, F., Pagliarini, E., Perugini, M., Barbieri, L., \& Guasti, M. T. (2016). Morphosyntax and logical abilities in Italian poor readers: The problem of SLI under-identification. First Language, 36(3), 295-315.

Bishop, D. V. M., McDonald, D., Bird, S., \& Hayiou-Thomas, M. (2009). Children who read words accurately despite language impairment: Who are they and how do they do it? Child Development, 80, 593-605.

Bowers, P. N., Kirby, J. R., \& Deacon, S. H. (2010). The effects of morphological instruction on literacy skills: A systematic review of the literature. Review of Educational Research, 80, 144-179.

Cain, K. (2007). Syntactic awareness and reading ability: Is there any evidence for a special relationship? Applied Psycholinguistics, $28,679-694$.

Cantiani, C., Lorusso, M. L., Perego, P., Molteni, M., \& Guasti, M. T. (2013). Event-related potentials reveal anomalous morphosyntactic processing in developmental dyslexia. Applied Psycholinguistics, 34, 1135-1162.

Cantiani, C., Lorusso, M. L., Perego, P., Molteni, M., \& Guasti, M. T. (2015). Developmental dyslexia with and without language impairment: ERPs reveal qualitative differences in morphosyntactic processing. Dev Neuropsychol, 40(5), 291-312

Catts, H. W., Fey, M. E., Zhang, X., \& Tomblin, J. B. (1999). Language basis of reading and reading disabilities: Evidence from a longitudinal investigation. Scientific Studies of Reading, 3(4), 331-361.

Chik, P. P., Ho, C. S., Yeung, P., Wong, Y., Chan, D. W., Chung, K. K., \& Lo, L. (2010). Contribution of discourse and morphosyntax skills to reading comprehension in Chinese dyslexic and typically developing children. Annals of Dyslexia, 62(1), 1-18.

Dandache, S., Wouters, J., Ghesquière, P. (2014). Development of reading and phonological skills of children at family risk for dyslexia: A longitudinal analysis from kindergarten to sixth grade. Dyslexia, 20(4), 305-329.

Delimehmet-Dada, Ş. ve Ergül, C. (2020). Öğrenme güçlüğü olan ve olmayan öğrencilerin sözcük bilgisi ve okuduğunu anlama becerileri arasındaki ilişki. Ankara Üniversitesi Eğitim Bilimleri Fakültesi Özel Eğitim Dergisi, 21(1), 1-22.

Elwér, Å., Keenan, J. M., Olson, R. K., Byrne, B., \& Samuelsson, S. (2013). Longitudinal stability and predictors of poor oral comprehenders and poor decoders. Journal of Experimental Child Psychology, 115(3), 497-516.

Hulme, C., \& Snowling, M. J. (2016). Reading disorders and dyslexia. Current Opinion in Pediatrics, 28(6), 731-735.

Hulme, C., Nash, H. M., Gooch, D., Lervåg, A., \& Snowling, M. J. (2015). The foundations of literacy development in children at familial risk of dyslexia. Psychological Science, 26(12), 1877-1886.

Joanisse, M. F., Manis, F. R., Keating, P., \& Seidenberg, M. S. (2000). Language deficits in dyslexic children: Speech perception, phonology, and morphology. Journal of Experimental Child Psychology, 77(1), 30-60.

Karasar, N. (2010). Bilimsel araştırma yöntemi (20. baskı). Ankara: Nobel Yayınevi.

Knoop-van Campen, C. A. N., Segers, E., \& Verhoeven, L. (2018). How phonological awareness mediates the relation between working memory and word reading efficiency in children with dyslexia. Dyslexia, 24(2), 156-169.

Leonard, L. B. (2014). Children with specific language impairment. Cambridge, MA: MIT Press.

Lyon, G. R., Shaywitz, S. E., \& Shaywitz, B. A. (2003). Defining dyslexia, comorbidity, teachers' knowledge of language and reading: A definition of dyslexia. Annals of Dyslexia, 53, 1-14.

Lyytinen, P., \& Lyytinen, H. (2004). Growth and predictive relations of vocabulary and inflectional morphology in children with and without familial risk for dyslexia. Applied Psycholinguistics, 25(3), 397-411.

McArthur G. M., Hogben J. H., Edwards V. T., Heath S. M., \& Mengler E. D. (2000). On the "specifics" of specific reading disability and specific language impairment. Journal of Child Psychology and Psychiatry, and Allied Disciplines, 41(7), 869-874.

Moll, K., Hulme, C., Nag, S., \& Snowling, M. J. (2013). Sentence repetition as a marker of language skills in children with dyslexia. Applied Psycholinguistics, 36(2), 203-221.

Moura, O., Moreno, J., Pereira, M., \& Simões, M. R. (2015). Developmental dyslexia and phonological processing in European Portuguese orthography. Dyslexia, 21(1), 60-79.

Nation, K. J., Cocksey, J., Taylor, J. S. H., \& Bishop, D. V. M. (2010). A longitudinal investigation of early reading and language skills in children with poor reading comprehension. Journal of Child Psychology and Psychiatry 51(9), 1031-1039.

Oakhill, J. V., Cain, K., \& Bryant, P. E. (2003). The dissociationof word reading and text comprehension: Evidence from component skills. Language and Cognitive Processes, 18, 443-468.

Plaza, M., Cohen, H.,\& Chevrie-Muller, C. (2002). Oral language deficits in dyslexic children: weaknesses in working memory and verbal planning. Brain Cogn., 48(2-3), 505-512.

Ricketts, J., Nation, K., \& Bishop, D. V. M. (2007). Vocabulary is important for some, but not all reading skills. Scientific Studies of Reading, 11(3), 235-257.

Seçkin Yılmaz, Ş. ve Baydık, B. (2020). Comparison of language skills of students with and without reading difficulties. Ilkogretim Online Elementary Education Online, 19(2), 782-802.

Topbaş, S. ve Güven, O. S. (2017). Türkçe okul çağı dil gelişim testi. Detay Yayıncılık: Ankara.

Van der Lely, H. K. J., \& Marshall, C. R. (2010). Assessing component language deficits in the early detection of reading difficulty risk. Journal of Learning Disabilities, 43(4), 357-368.

Verhoeven, L., \& Perfetti, C. A. (2011). Introduction to this special issue: Vocabulary growth and reading skill. Scientific Studies of Reading, $15(1), 1-7$.

Wimmer, H. \& Schurz, M. (2010). Dyslexia in regular orthographies: Manifestation and causation. Dyslexia, 16, $283-299$.

Yıldıım, H. H. ve Yıldırım, S. (2011). Hipotez testi, güven aralığı, etki büyüklüğü ve merkezi olmayan olasılık dağılımları üzerine. Ilköğretim Online 10(3), 1112-1123.

Ziegler, J. C., Perry, C., Ma-Wyatt, A., Ladner, D., \& Schulte-Körne, G. (2003). Developmental dyslexia in different languages: Language-specific or universal? Journal of Experimental Child Psychology, 86, 169-193. 